The importance of the past...

\section{The importance of the past in public health}

\section{Virginia Berridge, Martin Gorsky}

\section{This issue contains a paper by Scally and Womack that emphasises the need to expand historical knowledge and understanding in the public health profession.}

$\checkmark$ is his editorial comments on a paper by Scally and Womack in the same issue. ${ }^{1}$ It announces the establishment of a new journal series on history. It reports the launch of the Centre for History in Public Health at the London School of Hygiene and Tropical Medicine. It summarises the launch lecture on the importance of history in the assessment of globalisation. It argues for more involvement of history and historians in the teaching of public health professionals and for revision of the professional curriculum.

There are some recent and forthcoming developments on this front. The authors mention the lack of a regular historical series in public health journals, with the notable exception of the American Journal of Public Health's long running "Public Health Then and Now". There will be a new historical series, "Public Health Past and Present" in the Journal of Epidemiology and Community Health. Contributions are welcome on any topic relevant to the subject. We hope to publish short research based papers that will enable historians to interact with the public health field and vice versa.

Exchanges between the two fields have been taking place in other ways. The launch of the new Centre for History in Public Health at the London School of Hygiene and Tropical Medicine in November 2003 has the aim of strengthening the links between historians and public health professionals. It builds on past joint work, for example the witness seminars and conferences on the Black Report on health inequalities, famous for being commissioned by a Labour government in the late 1970s and then "buried" by an incoming Conservative government; the career of Jerry Morris; and the "great smog" of $1952 .^{2}$

The launch lecture of the Centre, given by Simon Szreter of the University of Cambridge was on "Public health and security in an age of globalising economic growth: the awkward lessons of history". Szreter proposed that there have been several earlier phases of globalisation in world history, including the colonial encounters of the early modern era and the massive expansion of world trade consequent upon industrialisation. He raised the question of what could be learnt from these earlier experiences about the implications of globalisation for world health. Was the effect broadly positive, with growth in trade and productivity increasing individual wealth and thus wellbeing? Or was it broadly negative, as urbanisation and greater mobility increased exposure to epidemic disease? Szreter argued forcefully that the evidence favoured the second scenario, and the message of his lecture was that only the countervailing forces of government and civil society could avert the deleterious health consequences of globalisation today.

His thesis was developed through a detailed exposition of the British case, which traced the development of a social welfare infrastructure that contributed to rising life expectation. He noted the beneficial impact of the poor laws in the 17th and 18th centuries, which he viewed as a key factor underpinning the productivity gains in the agricultural sector, which in turn provided the basis for Britain's early industrial take off. Turning to the 19th century, he then set out his attack on the McKeown thesis, which argues that improved nutritional status explains the greater part of the mortality decline from the last quarter of the century. Szreter's account foregrounds instead the role of public health reform, and he emphasised that this was not simply the result of initiatives by "great" individuals such as Chadwick and Snow. It was brought about by the committed work of local government officials and public health doctors, who in turn were responding to popular support for social action emanating from voluntary associations such as trade unions, friendly societies, and campaigning groups. ${ }^{3}$ Democracy and a thriving civil society were therefore crucial to public health improvement. These are historical issues with many contemporary implications and correspond with the focus of networks at the local level that is also featured in the Scally and Womack paper. ${ }^{1}$

For further details of the Centre and its launch visit its web pages (http:// www.lshtm.ac.uk/history).

Input such as this on the "big picture" from historians is vital. The Centre is a partner organisation in the history and policy web site (http:// www.historyandpolicy.org), which aims to bring historical perspectives to bear on present day policy issues. Britain's Royal Historical Society recently organised a conference on the topic of "What Can Historians Contribute to Public Debate?" Historical interest is at a high point, at least among the public in the UK. Historians are drawn upon for comment on policy issues, as the coverage of the Iraq war has shown.

This interest extends to health matters. The British Secretary of State for Health, Dr John Reid, a historian by training, has recently published a pamphlet on localism in health that draws on local working class traditions of mutualism to justify the establishment of foundation hospitals. ${ }^{4}$ The government's Wanless inquiry into public health is also taking historical analysis on board.

These developments are by no means unproblematic. The relation of history with policy can see policy agendas determining the lessons of history that are used. Historical interpretation and understanding can run the risk of becoming a policy poodle. Intense media interest in health crises can surprise and

\section{Key points}

- The journal is launching a new history series and contributions are invited.

- A new Centre for History in Public Health has been established at the London School of Hygiene and Tropical Medicine.

- Its launch lecture was a powerful historical critique of the connection between globalisation and economic growth. Civic society was historically important.

- History teaching for public health professionals is important but neglected in the professional curriculum. This needs to be remedied. 


\section{Policy implications}

Implications for training in public health.

almost overwhelm historians who get involved, as the valuable role of historical analysis in the 2001 foot and mouth epidemic showed. ${ }^{5}$

Scally and Womack's paper recalls the role of history teaching of public health professionals by Sidney Chave. They mention the history study unit we run at the London School of Hygiene and Tropical Medicine. Nevertheless history struggles to find a role in the increasingly crowded training curriculum. Search the UK Faculty of Public Health web site training sections and you will find little, if any, reference to history. Health economics, epidemiology, statistics, the "behavioural sciences" (not history) now take precedence. The emphasis is on the here and nowvaluable, but it does not lead us to question how we got to the present and how the past may offer different models. This is an area that urgently needs to be looked at and to be built in more centrally to public health training. Some medical and public health schools already have professional historians in post and others could follow this example. The professional training curriculums could be revised to incorporate history.

There is still much that remains to be done to increase the interaction of history with public health. Multidisciplinary public health is the latest variant of a long series of historical reconstructions. Is it willing to subject itself to the lens of history?

\section{ACKNOWLEDGEMENTS}

We acknowledge the support of the Wellcome Trust whose historical research funding sup- ports much of the work of the Centre for History in Public Health.

\section{$J$ Epidemiol Community Health 2004;58:728-729.}

doi: 10.1136/jech.2003.019141

Correspondence to: Professor V Berridge, Centre for History in Public Health, London School of Hygiene and Tropical Medicine, London, UK; virginia.berridge@lshtm.ac.uk

\section{REFERENCES}

1 Scally G, Womack J. The importance of the past in public health. J Epidemiol Community Health 2004;58:751-5

2 Berridge V, Blume S, eds. Poor health. Social inequality before and after the Black Report. London: Frank Cass, 2003.

3 Szreter S. The importance of social intervention in Britain's mortality decline c1850-1914: a reinterpretation of the role of public health. Soc Hist Med 1988:1:1-37.

4 Reid J. Localising the National Health Service. Gaining greater equity through localism and diversity. London: New Local Government Network, New Health Network, 2003.

5 Berridge V. Public or policy understanding of history? Soc Hist Med 2003;16:511-23.

\section{Intervening in communities: challenges for public health}

\section{Helen Roberts}

\section{There is still a long way to go in developing and implementing sound interventions at a community level}

$\mathrm{T}$ here used to be a touching belief that public health interventions were exempt from the kind of scrutiny that we might normally expect to be a pre-requisite for messing around with peoples' bodies and their lives. ${ }^{1}$ Even once it became accepted that physicians and surgeons could inadvertently do more harm than good, some areas of public health and health promotion occupied a privileged place. A few leaflets here, telling parents how to do their jobs better, a bit of social engineering there, trying to iron out a little local difficulty with housing or transport. What could be the harm in that? So long as people's hearts were in the right place, brains were not thought to need to be quite so fully engaged in changing communities as in changing lipid lowering medication.

All that is now starting to change. The public health field of the Cochrane Collaboration is producing guidelines for those working in public health; the UK Medical Research Council ${ }^{2}$ has produced guidelines on complex interventions, including those delivered at a population level for health promotion purposes, the Campbell Collaboration, which is a sister collaboration to Cochrane, but producing reviews in education, social welfare, and crime prevention is looking at the effectiveness of policies and practices ranging from boot camps for young offenders to mentoring.

Over the past few years, randomised controlled trials of day care, ${ }^{3}$ social support in pregnancy, ${ }^{4}$ sex education, ${ }^{5}$ and smoke alarms ${ }^{6}$ are among the studies conducted in non-clinical settings, with a public health purpose. Epidemiologists and social scientists working in tandem have ensured that as well as reporting health outcomes, issues of process and implementation are also considered. The qualitative methods group in Cochrane is leading some of the work on this ${ }^{7}$ at the same time as hierarchies of evidence are being challenged $^{8}$ with a greater focus on using the right kinds of methods and design for the particular question being explored. No longer are randomised controlled trials seen to trump other methods in all circumstances, or qualitative work seen simply as a way of trying to get the patients to comply, and understand why they don't.

No randomised controlled trial is entirely simple. However straightforward the intervention, human creativity and cunning knows no bounds in subverting random allocation. William Silverman's wonderful story of attempts to undermine a trial of the use of oxygen in premature babies illustrates this. ${ }^{9}$ Different coloured marbles would be returned to the dish if they were the "wrong" colour for a baby thought to need the intervention; allocations in sealed envelopes would be held up to the light. Of course we don't do things that way these days, but if there are problems with even relatively straightforward interventions in relatively well organised clinical settings, the problems of large scale community trials are even greater.

Archie Cochrane was there first, of course. He described the gap between the scientific measurements based on randomised controlled trials and the measurements of benefit in the community. "There is", he wrote, "a gulf which has been much underestimated." ${ }^{\prime 10}$ The article by Penny Hawe and her colleagues in this issue is therefore a welcome addition to the relatively sparse community trials literature to which her group has already substantially contributed. ${ }^{11}$ Their piece, 
which is based on a cluster randomised controlled trial of primary and community development intervention to promote the health of mothers and babies, describes a mixed methods study designed to explore how context may affect the uptake, success, and sustainability of interventions. Their ambitious aim is to find out more about what aspects of context seem to matter most, and the ways in which that might lead to adjusting the intervention-the community equivalent of dose titration. They rightly point out that when it looks as if a complex intervention may have "worked", it is difficult, if not impossible, to work out which bit has worked and why.

The evaluation of Sure Start, ${ }^{12}$ the UK early intervention programme designed to achieve better outcomes for children through increasing the availability of childcare, improving health, educational, and emotional development for children and supporting parents, is a case in point. The outcomes are described as being to meet their needs and stretch their aspirations. Perhaps the most central outcome is that of enabling children to thrive once they enter primary school. Although the evaluators' meticulous design will undoubtedly add to our knowledge of how some parts of the programme work, and what some of the strengths and weaknesses are for particular processes, the design and implementation of the Sure Start programme as a whole means that they will not be in a position to tell us just what works in terms of particular interventions leading to particular outcomes for

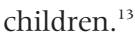

Hawe et al point out that the outcomes of many community intervention trials have been small or non-significant. ${ }^{11}$ They suggest that better planning and theorising might improve these. There are other explanations though. Modest interventions do often have modest effects, and it may simply be that the things that can be done in the context of community interventions simply cannot adequately compete against other powerful forces, such as poverty and inequality. But even a small effect in a community may have a positive benefit at a population level, and it is in thinking about how this can best be done, and understanding levers and barriers in the ways described by Hawe and her colleagues, that progress is likely to be made. The kind of careful work described in their article on understanding implementation variation is likely to take us further in going beyond the vote counting of number of media messages received and numbers of leaflets printed and distributed.

It is important meanwhile not to ignore the fact that public health interventions at a community level may themselves have adverse effects. On the one hand, people may feel invaded or under surveillance, while on the other, active community members can be seen by professionals as a threat rather than a resource. Building social capital and building trust are important, but as one community activist put it, "Keeping children safe here is like teaching a child to swim in a pool full of alligators. The social workers and community workers are in and out of the place in their cars the whole time. The wains [children] can't play safely." (personal communication, Walter Morrison, Corkerhill). In the same community, a group of mothers suggested that the best thing that could be done with the many leaflets they were given telling children how to cross the road was to use them to make papier mache road humps. ${ }^{14}$

For us to understand more, we need to be franker about failure as well as success; about problems as well as solutions. But funding imperatives make this difficult and dangerous. To sustain funding, there are considerable pressures to present every initiative as a success and to create a fairy story. The components of the interventions described by Hawe et al all have face validity, and the potential for long term gains. The careful qualitative and quantitative methods they describe have the potential to engender good reflective practice.

We still have a long way to go in developing and implementing sound interventions at a community level. We need to know much more about using the expertise of people who live in poor communities, and who for the most part enjoy considerable success in bringing up families in conditions of adversity. We need to be more savvy about appropriate methodological triage, and develop potential interventions in a step-wise manner, with the more expensive components preceded by sound qualitative work to enable investigators to develop interventions that mean something to those on the receiving end.

Big public health problems such as the "epidemic" of obesity, social and emotional difficulties experienced by children and young people, people coming to parenthood before they are ready, smoking and alcohol use, and growing inequalities in health mean that public health is moving up the agenda. In the
UK for instance, the recent Wanless report $^{15}$ advocates the importance of moving from a position where we know a good deal about the determinants of poor health to knowing more about what we can actually do about it, and strengthening the evidence base for public health policy and practice. While there may be more focus on individual change, and less on some of the big social drivers and obstacles than some of us would like, in general, he advocates precisely the kinds of work to improve our knowledge of effective implementation described in this issue.

\section{$J$ Epidemiol Community Health}

2004;58:729-730.

doi: 10.1136/jech.2004.020347

Correspondence to: Professor H Roberts, Child Health Research and Policy Unit, Institute for Health Sciences, 20 Bartholomew Close, London ECIA 7QN, UK; h.roberts@city.ac.uk

Competing interests: I work on community interventions, and have been funded in the past, and currently to work on inequalities in health, and mixed methods in trials.

\section{REFERENCES}

1 Skrabanek $\mathbf{P}$. Why is preventive medicine exempted from ethical constraints? J Med Ethics 1990;16:187-90.

2 Medical Research Council. http:// www.mrc.ac.uk/prn/pdf-mrc_cpr.pdf (see page 3) (Accessed 21 May 2004).

3 Zoritch B, Roberts I, Oakley A. Day care for preschool children. Cochrane Library. Issue 1. Chichester: Wiley, 2004.

4 Oakley A, Rajan L, Grant A. Social support and pregnancy outcome: report of a randomised controlled trial. Br J Obstet Gynaecol 1990;97:155-62.

5 Wight D, Raab GM, Henderson M, et al. Limits of teacher delivered sex education: interim behavioural outcomes from randomised trial. BMJ 2002;324:1430.

6 Rowland D, DiGuiseppi C, Roberts I, et al. Increasing the prevalence of working smoke alarms in disadvantaged inner city housing: a randomised controlled trial. BMJ 2002;325:998-1001.

7 Cochrane Collaboration. http:// mysite.freeserve.com/Cochrane_Qual_Method/ index.htm (accessed 8 Mar 2004)

8 Petticrew M, Roberts H. Evidence, hierarchies and typologies: horses for courses. J Epidemiol Community Health 2003;57:527-9.

9 Silverman WA. Retrolental fibroplasia: a modern parable. New York: Grune and Stratton, 1980.

10 Cochrane AL. Effectiveness and efficiency. Random reflections on health services. London: Nuffield Provincial Hospitals Trust, 1972.

11 Hawe P, Shiell A, Riley T, et al. Methods for exploring implementation variation and local context within a cluster randomised community intervention trial. J Epidemiol Community Health 2004;58:788-93.

12 Sure Start. http://www.surestart.gov.uk/ aboutsurestart/ (accessed 21 May 2004)

13 National Evaluation of Sure Start. http:// www.ness.bbk.ac.uk/ (accessed 21 May 2004)

14 Roberts H, Smith SJ, Bryce C. Children at risk: safety as social value. Buckingham: Open University Books, 1995.

15 The Treasury. http://www.hm-treasury.gov.uk/ Consultations and Legislation/wanless/ consult_wanless_final.cfm (accessed 21 May 2004). 


\section{Sixth version of the "Uniform Requirements for Manuscripts Submitted to Biomedical Journals": lots of ethics, some new recommendations for manuscript preparation}

\section{Ana M García}

\section{Formal education on publication and on publication ethics is an important gap in health careers}

I November 2003, the International Committee of Medical Journal Editors (ICMJE) published a revised version of their Uniform Requirements for manuscripts, first launched in 1979 by a small group of editors of general medical journals then simply named the Vancouver Group. This committee has produced six editions of the Uniform Requirements, the last one reviewing the whole document and including in the text a number of separate statements published independently by the ICMJE in the past years. ${ }^{1}$ The fifth edition was published in $1997 .^{2}$

More than a half of the present document is devoted to ethical principles related to the process of evaluating and publishing manuscripts in biomedical journals and the relationships between editors, authors, peer reviewers, advertisers, and the media. A considered reading of the text is recommended mostly to editors, authors, and readers of biomedical literature; some main contents are commented on below.

Ethical principles in science publication are as critical as ethical principles in research conduct. Publication is an ultimate stage of scientific research; in fact, as it has been stated, science does not exist until it is published. ${ }^{3}$ Scientists have a critical role in most of today's societies, which are firm believers in science dictations. Health sciences, moreover, deal with very sensitive constituents of people's happiness and welfare. Hence, it would be desirable that researchers strictly respect conduct principles to better serve the interests of the community and to causing no damage.

Among the several ethical issues discussed by the ICJME, authorship is probably one of the major fields for misconduct in biomedical publication, and in which more discrepancies are to be found among researchers, and also among authors and editors. Also it should be said that most of the time misconducts regarding authorship will have no important consequences for the public's health, but they have an effect on the public perception on the reliability on biomedical science.

Perhaps most of the authors in biomedical sciences simply do not know authorship criteria. Perhaps only readers keen on publication theoretical aspects, the same people who are already familiar and reflective over issues such as authorship, are now reading this editorial. In a survey of 66 researchers from a university medical faculty in Britain ${ }^{4}$ half of them with more than 30 published papers-only five respondents were able to quote all three criteria of the ICMJE for authorship, and only one knew that all three criteria were required to credit authorship. We believe that formal education on publication and on publication ethics is an important gap in health careers. But as most of the "authors" of biomedical articles ignore or directly flout common rules regarding authorship, it could make sense first to ask: Do we need any criteria for authorship? And if so, what kind of criteria do we need?

We do think that we need some criteria. And that the criteria by the ICJME are good enough. The key issue is to guarantee public responsibility for the published information, if really not feasible for every author for the full manuscript, at least of every contributor to the parts in which he or she has participated. But it would be necessary too for at least the designation of a "guarantor" or main person responsible for the work as a whole, as it has been said emulating "ministerial responsibility". ${ }^{5}$ The ICJME criteria fit this approach: they no longer claim for "public responsibility for the content" to each author of a paper, as in the 1997 edition. They refer to "substantive intellectual contributions" for the authors and they recommend the identification of at least one person "responsible for the integrity of the work as a whole". The famous three criteria for authorship credit ("1. Substantial contributions to conception and design, or acquisition of data, or analysis and interpretation of data; 2 . Drafting the article or revising it critically for important intellectual content; and 3. Final approval of the version to be published. Authors should meet conditions 1, 2, and 3") are still in this version of the document with only minor variations: the words "or acquisition of data" were not in the fifth edition. This criterion was added by the ICMJE in 2000 as a separate statement after the experience of the Lancet in disclosing the contributions of their authors: it was noticed that the criteria for authorship outlined by the ICJME were not completely congruent with the self identified contributions of researchers. ${ }^{6}$ Although the claim to accomplish all the three conditions has been criticised by editors ${ }^{7}$ and authors, ${ }^{4}$ in fact criteria (2) and (3) are not strict nor "astonishing out of touch", as it has been stated, ${ }^{7}$ but rather attainable by any category of coauthor. The key issue is then accomplishing the first criterion; and to keep in mind the necessary public responsibility for the whole or appropriate contents of the work. It is worth remembering that the acknowledgements section is a wonderful place to recognise any kind of contribution to the work-for everybody participating in the study to feel that their work has been fairly and publicly acknowledged, as respectable as the byline under the title. Curiously, contributions in the acknowledgements section are commonly described in detail, but the same is the exception for contributions in the byline.

Conflict of interest is another ethical issue profusely discussed in the ICMJE document as related to individual authors' commitments, to project support, or to commitments of editors, journal staff, or reviewers. As defined by the ICMJE, conflict of interests exits when "an author (or the author's institution), reviewer or editor has financial or personal relationships that inappropriately influence (bias) his or her actions (...). These relationships vary from those with negligible potential to those with great potential to influence judgement, and not all relationships represent true conflict of interest. The potential for conflict of interest can exist whether or not an individual believes that the relationship affects his or her scientific judgement". 
The interest of the committee in the disclosure of any potential conflict of interest has led to the recommendation of including in the manuscript a page for the notification of conflict of interest as a part of the manuscript, following the title page, "to prevent the information on potential conflict of interest for authors from being overlooked or misplaced". In the online system for the submission of manuscripts to the Journal of Epidemiology and Community Health authors are prompted to declare if there is or there is not any potential conflict of interest regarding their work. However, our experience shows that authors declaring conflict of interest are a minority. This can be because conflict of interest is not frequent among our authors or because disclosure of conflict of interest is not yet a common practice among them, whatever the reasons. The British Medical Journal has developed very active policies in relation to conflict of interest, including authors, editors, reviewers, and journal staff. Interested readers can consult the editorial policy and recommendations regarding disclosure of conflict of interest on the BMJ web site (http://www.bmj.com). But also according to the experience of this journal, authors declare conflict of interests only rarely.

It seems sensible to hypothesise that conflict of interest, or a conflict between the private interests and the official or public responsibilities of a person in a position of trust, ${ }^{8}$ can be quite frequent in relation to biomedical publication. Focusing on authors, almost everyone will have personal interests in career advancement, academic promotion, or future research funding not necessarily related to the public interest on the availability of relevant and useful scientific knowledge. This is quite a tricky situation. For example, should an investigator declare that he or she is particularly prompted to publish because it is very convenient for an approaching chance of academic promotion? Also, although we have not found this category in the usual lists of situations with a potential of conflict of interest: love (for example, between editors and authors) could be a cause of conflict of interests (that is, bias inappropriately editorial decisions). But for the moment, we do not think it is necessary for editors and authors to disclose publicly their love interests. However, public trust on scientific conduct and publication practices could be easily damaged by these common place situations, we as health researchers (enjoying a significant public trust) should not forget it.

Non-financial (or non-directly financial) conflicts of interest could be very difficult to handle. As it is not habitual to declare any kind of conflicts, the discloser seems immediately suspicious. But occurrence of conflict of interest is not synonymous of misconduct: a researcher can become immensely rich, let's say, as a consequence of a published discovery, without transgressing any ethical principle in the conduction and publication of the study. However, the right procedure is to disclose any previous relationships that could be affected by the performance or the publication of the study.

Becoming immensely rich is not a frequent risk among public health researchers. Most of the famous cases of conflict of interests are related to research on drugs. But also public health issues are frequently related to strong financial interest, tobacco is only one of several examples. As stated by Richard Smith, transparency is the key. And the emphasis should be on disclosure of conflict of interest associated to financial relationships, as these are "the most easily identifiable forms of conflict of interest and the most likely to undermine the credibility of the journal", according to the ICMJE. However, as long as disclosure of conflict of interest is not common, authors will continue to be reluctant to expose themselves to the suspicious of editors and readers. More knowledge is needed on the effects of disclosure and not disclosure of conflict of interest, as well as more education on these practices for everyone.

Several other interesting recommendations related to ethical issues are discussed in the ICMJE document, as they state, "based largely on the shared experience of a moderate number of editors and authors, collected over many years" and "accompanied by a rationale that justifies them". It is not possible to comment here on every aspect presented in the document (editorial freedom, peer review, overlapping publication, electronic publishing, medical journals, and the media, etc) and again we recommend a thorough reading of the full text.

Lastly, this edition of the Uniform Requirements also presents some new points regarding manuscript preparation that deserve attention. Authors are encouraged to follow reporting guidelines relevant to their specific research design, and a reference is done to the CONSORT statement. For observational research, the use of guidelines such as the proposal for reporting meta-analysis of epidemiological studies ${ }^{9}$ could be also worth considering. The ICMJE establish that manuscripts should be accompanied by a cover letter providing information on redundant publication, conflict of interests, or authorship if that information is not included elsewhere. If the manuscript has been previously rejected by another journal, it is recommended to include the previous editor's and reviewers' comments along with the authors' responses to these comments, a laudable procedure that may help editors to "expedite the review process" (perhaps even more than that would be desirable for the already rejected authors).

Some new recommendations relate to the use and citation of references in the manuscript. References to original research are preferred to references to review articles whenever possible. Extensive lists of references are claimed not to be necessary; moreover, we would suggest that these lists now could be indicative of intellectual laziness or poor literature knowledge by the part of the authors, and are not really useful to the readers (although surely contribute to increase individual's and journal's so called "impact" factors). The ICMJE has introduced some changes in the style of references; most noticeably, for articles in journals a full stop should be now added at the end of the journal's abbreviated title, and citation of changing electronic material on the internet should include, together with date of citation, the updated date of consulted information.

Writing and publishing in health sciences are necessary stages for the knowledge and diffusion of critical issues related to people's health and welfare. The sixth edition of the ICMJE Uniform Requirements establish some basic principles related to these tasks, which must be known for every actor in the scene: mostly authors, editors, and readers. The ICMJE document also contributes to the debate on many new and old issues related to publication in health sciences, basic ethical principles and other concerns. Although, as suspected by Davidoff ${ }^{3}$ it is likely that "we will still wrestling 50 years from now with the same patchwork, afterthe-fact, fundamentally unsatisfactory solutions to the same vexing ethical problems we are struggling with today".

$J$ Epidemiol Community Health 2004;58:731-733.

doi: 10.1136/jech.2004.024802

Correspondence to: Professor A M García, University of Valencia, Spain, Facultad de Ciencias Sociales Avda. Tarongers, s/n Valencia, Spain, 46022; anagar@uv.es

\section{REFERENCES}

1 International Committee of Medical Journal Editors. Uniform requirements for manuscripts submitted to biomedical journals: writing and editing for biomedical publication. hitp:// www.icmje.org/index.html (updated Nov 2003 cited 20041 May). 


\section{EDITORIALS}

2 International Committee of Medical Journal Editors. Uniform requirements for manuscripts submitted to biomedical journals. JAMA 1997:277:927-34.

3 Davidoff $F$. The other two cultures: how research and publishing can move forward together. In: HudsonJones A, McLellan F. Ethical issues in biomedical publication. Baltimore: The Johns Hopkins University Press, 2000:323-44.
4 Bhopal R, Rankin J, McColl E, et al. The vexed question of authorship: views of researchers in a British medical faculty. BMJ 1997;314:1009-12.

5 Smith R. Authorship is dying: long live to contributorship. BMJ 1997;315:696.

6 Rennie D, Flanagin A, Yank V. The contributions of authors. JAMA 2000;284:89-91.

7 Horton R, Smith R. Signing up for authorship. Lancet 1996;347:780.
8 Flanagin A. Conflict of interest. In: HudsonJones A, McLellan F. Ethical issues in biomedical publication. Baltimore: The Johns Hopkins University Press, 2000: 137-65.

9 Stroup DF, Berlin JA, Morton SC, et al. Metaanalysis of observational studies in epidemiology. A proposal for reporting. JAMA 2000;283:2008-12

\section{THE JECH GALLERY}

\section{Sweet smell of success}

\section{SUCCESSFUL TRADITIONAL METHODS}

In the medina of Fès, an acrid stink leads you to the tanneries, the most pungent souks (markets). Visitors grasp sprigs of mint to abate the smell. Redolent of medieval life, soft hides are stomped with red, yellow, and brown dyes. In the high noon sun or bone chilling air, men and boys squat over, or stand in the colourful (albeit toxic) giant vats.

A challenge in the informal sector, such as parts of Morocco's famous leather industry, is that it is less regulated, and perhaps, less safe. This raises the importance of smart choices, influenced by all the social, economic, and cultural factors that affect behaviour. Successful traditional methods can benefit from innovations, such as those that increase productivity and reduce pollution from heavy metal laden effluents. Large wastewater projects developed in Fès and Casablanca are evidence that plants for water treatment and recycling chromium can meet modern safety standards.

\section{EVOLUTION OF WORK ORGANISATION}

In some parts of the world, the organisation of work is moving from hierarchical to a flatter organisation. With this power shift, leadership is required of every worker, with the capacity to make independent decisions. On the bright side, a flatter organisation can offer workers more authority and autonomy. While increasing personal choice is generally attractive, when it comes to health and safety on the job, relying on individuals to protect themselves is the least desirable form of protection. The preference is to engineer hazards out of the workplace.

\section{ETHICAL ISSUES}

Eventually, codes of conduct need to be developed to protect health and safety of workers throughout the world. In the USA, most Fortune 500 companies already have codes of conduct or voluntary initiatives for socially responsible, sustainable business. Voluntary standards such as ISO 9000 for quality, ISO 14000 for environmental management, and the hazard analysis and critical control point (HACCP) food safety system are becoming mandatory for trade. By the same token, global standards need to reflect the current reality of labour, ${ }^{1}$ and promote health and safety with enlightened, fair minded policy.

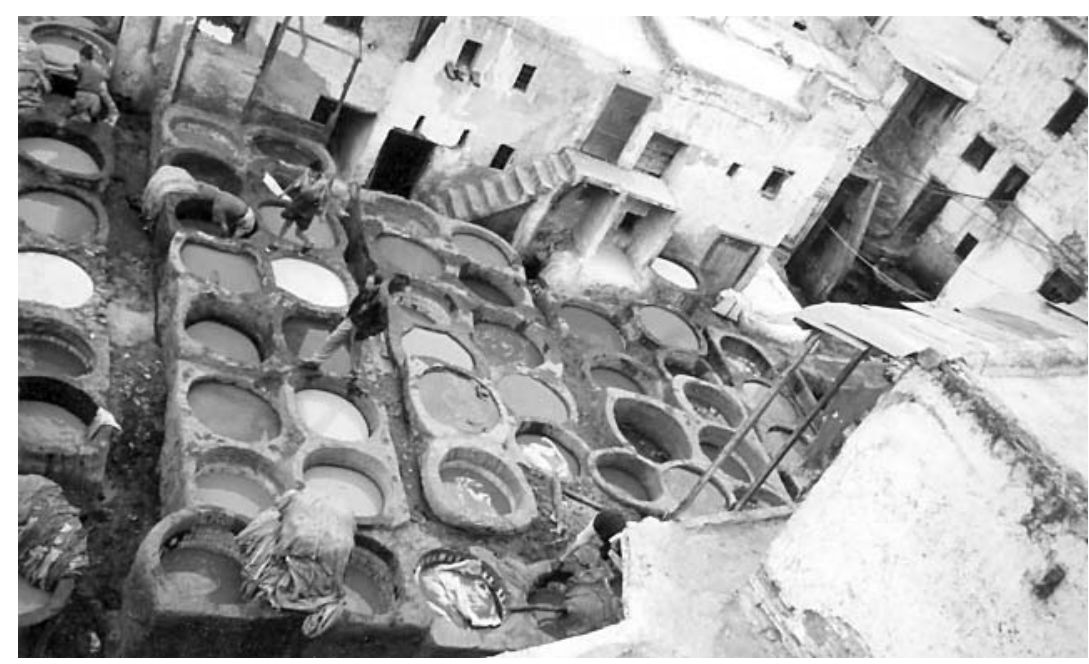

\section{FAIR TRADE LABELLING}

Thanks to concerted action by consumers and producers, fair trade certification is already available for certain agricultural products (for example, coffee, cocoa, sugar, bananas). Manufactured products are future candidates for Fairtrade certification. Ethical issues have boosted the Trade Justice Movement in the UK with the Fairtrade Labelling Organisations (FLO) outlining a range of international labour standards and health and safety requirements. In the USA and Canada, Fair Trade is marketed via Ten Thousand Villages, SERRV, Equal Exchange, Global Exchange, and Bridgehead. With impressive buying power, consumers may yet have the greatest impact on how products are manufactured and food is grown, how items are processed and delivered, and ultimately, who profits in the scheme of things.

\section{PRINCIPLES OF ECONOMIC AND SOCIAL JUSTICE}

Unfortunately, low literacy and low levels of training in many areas dampen available choices or hopes of the sweet smell of success. Although awareness of health and safety problems is low among workers in the informal sector, awareness of ways to improve working conditions is even lower. Clearly, the reward of formal education in developing skills is of great consequence. Progressive leaders can shape policies to comply with international labour standards (providing effective enforcement). Beneficiaries are the artisans and workers in the small scale industries, and those who purchase their wares.

Deborah F Salerno Clinical Communications Scientist, Pfizer Global Research and Development, Michigan Laboratories, 2800 Plymouth Road, Ann Arbor, Ml 48105, USA; deborah.salerno@pfizer.com

\section{REFERENCE}

1 London L, Kisting S. Ethical concerns in international occupational health and safety. Occup Med 2002; 17:587-600. 